\title{
Seeking peace of mind: paranoia and its therapy through nature in John Burnside's A Summer of Drowning
}

\begin{abstract}
This article examines the development of paranoia in John Burnside's A Summer of Drowning. The study will mainly focus on anxiety as the main cause of the protagonist's anxious feelings. The protagonist, Liv, suffers from paranoid feelings as a result of drowning her schoolmates. Consequently, she becomes psychically anxious.Her anxiety intensifies when she meets people whom she suspects of complicity in murdering her schoolmates. The study, in this respect, will follow a textual analysis of the protagonist's paranoia which constitutes her anxiety.It will provide a close reading of the protagonist's behaviors, feelings, and suspicion of other people.These behavioral attributes will be scrutinized as lucid indications of her psychic disorder. As such, Sigmund Freud's concept of anxiety is going to be applied in order to analyze the latent causes of the protagonist's anxiety, and paranoia thereof. The application of Freud's concept of anxiety will be detailed by discussing the psychoanalytical critical insights suitable to interpret anxiety and its negative effects upon the protagonist's behavior. She is triggered by her mother's predilection to nature, and she decides to resort to wild landscapes as exits for her paranoia.She prefers being away of people.Just so,she becomes aware of her natural surroundings, such as landscapes and meadows. Accordingly, Cheryll Glotfelty's concept of eco-consciousness and Greg Garrard's concept of dwelling will be utilized to analyze the novel's natural settings as exits for the protagonist's anxiety.Together, these concepts are going to be the interdisciplinary approach to explore the protagonist seeking of solace and peace of mind in nature.
\end{abstract}

Keyword: Anxiety; Dwelling; Eco-consciousness; Paranoia; Wilderness 